\title{
The effect of control measures on COVID-19 transmission in Italy: Comparison with Guangdong province in China
}

\author{
Pei-Yu Liu'+, Sha He ${ }^{1+}$, Li-Bin Rong² and San-Yi Tang ${ }^{1 *}$ (D)
}

\begin{abstract}
Background: COVID-19 has spread all around the world. Italy is one of the worst affected countries in Europe. Although there is a trend of relief, the epidemic situation hasn't stabilized yet. This study aims to investigate the dynamics of the disease spread in Italy and provide some suggestions on containing the epidemic.

Methods: We compared Italy's status at the outbreak stage and control measures with Guangdong Province in China by data observation and analysis. A modified autonomous SEIR model was used to study the COVID-19 epidemic and transmission potential during the early stage of the outbreak in Italy. We also utilized a time-dependent dynamic model to study the future disease dynamics in Italy. The impact of various non-pharmaceutical control measures on epidemic was investigated through uncertainty and sensitivity analyses.
\end{abstract}

Results: The comparison of specific measures implemented in the two places and the time when the measures were initiated shows that the initial prevention and control actions in Italy were not sufficiently timely and effective. We estimated parameter values based on available cumulative data and calculated the basic reproduction number to be 4.32 before the national lockdown in Italy. Based on the estimated parameter values, we performed numerical simulations to predict the epidemic trend and evaluate the impact of contact limitation, detection and diagnosis, and individual behavior change due to media coverage on the epidemic.

Conclusions: Italy was in a severe epidemic status and the control measures were not sufficiently timely and effective in the beginning. Non-pharmaceutical interventions, including contact restrictions and improvement of case recognition, play an important role in containing the COVID-19 epidemic. The effect of individual behavior changes due to media update of the outbreak cannot be ignored. For policy-makers, early and strict blockade measures, fast detection and improving media publicity are key to containing the epidemic.

Keywords: COVID-19, Cumulative cases, Control measures, Model prediction

*Correspondence: sytang@snnu.edu.cn

${ }^{\dagger}$ Pei-Yu Liu and Sha He contributed equally to this work.

'School of Mathematics and Information Science, Shaanxi Normal University,

710119 Xi'an, PR China

Full list of author information is available at the end of the article

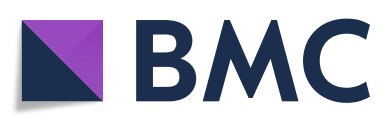

(c) The Author(s). 2020 Open Access This article is licensed under a Creative Commons Attribution 4.0 International License, which permits use, sharing, adaptation, distribution and reproduction in any medium or format, as long as you give appropriate credit to the original author(s) and the source, provide a link to the Creative Commons licence, and indicate if changes were made. The images or other third party material in this article are included in the article's Creative Commons licence, unless indicated otherwise in a credit line to the material. If material is not included in the article's Creative Commons licence and your intended use is not permitted by statutory regulation or exceeds the permitted use, you will need to obtain permission directly from the copyright holder. To view a copy of this licence, visit http://creativecommons.org/licenses/by/4.0/. The Creative Commons Public Domain Dedication waiver (http://creativecommons.org/publicdomain/zero/1.0/) applies to the data made available in this article, unless otherwise stated in a credit line to the data. 


\section{Background}

Six types of coronavirus have been found to be capable of causing human infections [1]. Four of them are not highly pathogenic, typically causing cold symptoms in immunocompetent individuals, while the other two types, the severe acute respiratory syndrome (SARS) and the Middle East respiratory syndrome (MERS), can result in severe respiratory illness and fatalities [2-4]. In late 2019, a novel coronavirus COVID-19, which turns out to be more infectious and can survive higher temperature than SARS [5], has been identified as the pathogen of an ongoing pandemic. This virus has spread to many countries in the world [6-9]. By May 31, 2020, more than 489921 confirmed cases due to COVID-19 had been reported in Eastern Mediterranean [10], Italy is one of the most hit countries with more than 232664 confirmed cases, which account for $47 \%$ of reported cases in Eastern Mediterranean. Although there is a trend of relief in Italy but the situation remains unstable. Control measures have been implemented in Italy aiming to contain the outbreak and the time-line of the changes of control strategy in Italy is shown in Fig. 1a.

In the course of dealing with the worldwide outbreak crisis, mathematical models have played an important role in providing policymakers with timely and crucial epidemiological information. Many models have been developed, for instance, using the transmission model of SARS $[11,12]$ to investigate the spread of SARS, the molecular SARS model to understand its molecular structure for biochemical function and drug design [13], and animal models of MERS to study how disease passes from animals to humans $[14,15]$. The media impact models illustrate how social media influences the propagation of SARS [16]. Mathematical models have also been developed to study the transmission of COVID-19 in response to this current crisis [17-20]. For example, He et al. have developed a discrete-time stochastic epidemic model with binomial distributions to study the transmission of COVID-19 [21]. Tang et al. used a deterministic compartmental model to investigate the COVID-19 epidemic in the mainland of China, the Guangdong province of China, and Republic of Korea [22, 23]. The control measures and the timings of initiation in China might provide some suggestions to other countries [24]. Fang et al. adopted the model of susceptible-exposed-infectious-recovered (SEIR) with a data-driven analysis to study the effectiveness of government interventions in China [25].

What's the transmission dynamics of the COVID-19 and what is the impact of non-pharmaceutical control measures on the COVID-19 epidemic in Italy? In order to address the above problems in more detail, we choose Guangdong Province (the most developed province in China, and the population is nearly twice that of Italy [26, 27]) for comparative study to reveal the timeliness and effectiveness of the comprehensive prevention and control strategies. In this paper, we compare the strategies in the two places by analyzing their specific control measures, the change of cumulative cases, new cases, prevalence ratio and cure ratio, and further reveal the epidemic situation in the world and Europe through the observation and analysis of cumulative confirmed cases. We develop a modified autonomous SEIR model to investigate the early transmission dynamic in Italy. Considering the continuous effects of prevention actions, we incorporate piecewise functions for the contact and diagnosis rate into previous autonomous model and develop a time-dependent dynamic model. We assess the impact of the control measure's delayed effect, the decrease rate in the contact rate, the diagnosis rate under different control intensity and the strength of the public's awareness by uncertainty and sensitivity analyses. We also predict the peak time and number of cases under various measures. At last, based on parameter estimates we evaluate the prediction by fitting the model to the latest data up to May 31, 2020.

\section{Methods}

\section{Collection of cases data}

We obtained data of confirmed COVID-19 cases that were reported in Guangdong province, Italy and other places in the world from the Health Commission of Guangdong Province, the Ministry of Health of Italy, and the World Health Organization [28-31]. The data include infected cases in the world and Europe since January 26 to March 12,2020 , the cumulative confirmed cases, newly reported cases, death cases, and recovered cases in Italy from January 30 to March 13, 2020 and in Guangdong from January 19 to February 26, 2020. The number of cumulative confirmed cases in Italy was 2 between January 30 and February 5, 2020, and was 3 from February 5 to February 19,2020 . The numbers of cumulative death and recovered cases were 0 from January 30 to February 19, 2020. We exclude the data in these periods and will focus on the Italian data between February 20 and March 13 because this is the early stage of the Italian outbreak, which allows us to compare the effectiveness of the prevention and control measures used in Italy and Guangdong by analysis of those datasets.

\section{Time-line of control measures}

In Fig. 1, we select February 20 as the first day when there were 4 cumulative confirmed cases in Italy, and January 19 as the first day when Guangdong had one cumulative confirmed case. On February 28 Italy closed schools in Lombardy, the most serious epidemic area, when the number of cumulative confirmed cases was already 650 (Fig. 1a). This number is similar to the confirmed cases (i.e. 683) in Guangdong on February 2. In comparison, the Guangdong government took "Seven Measures" policy 


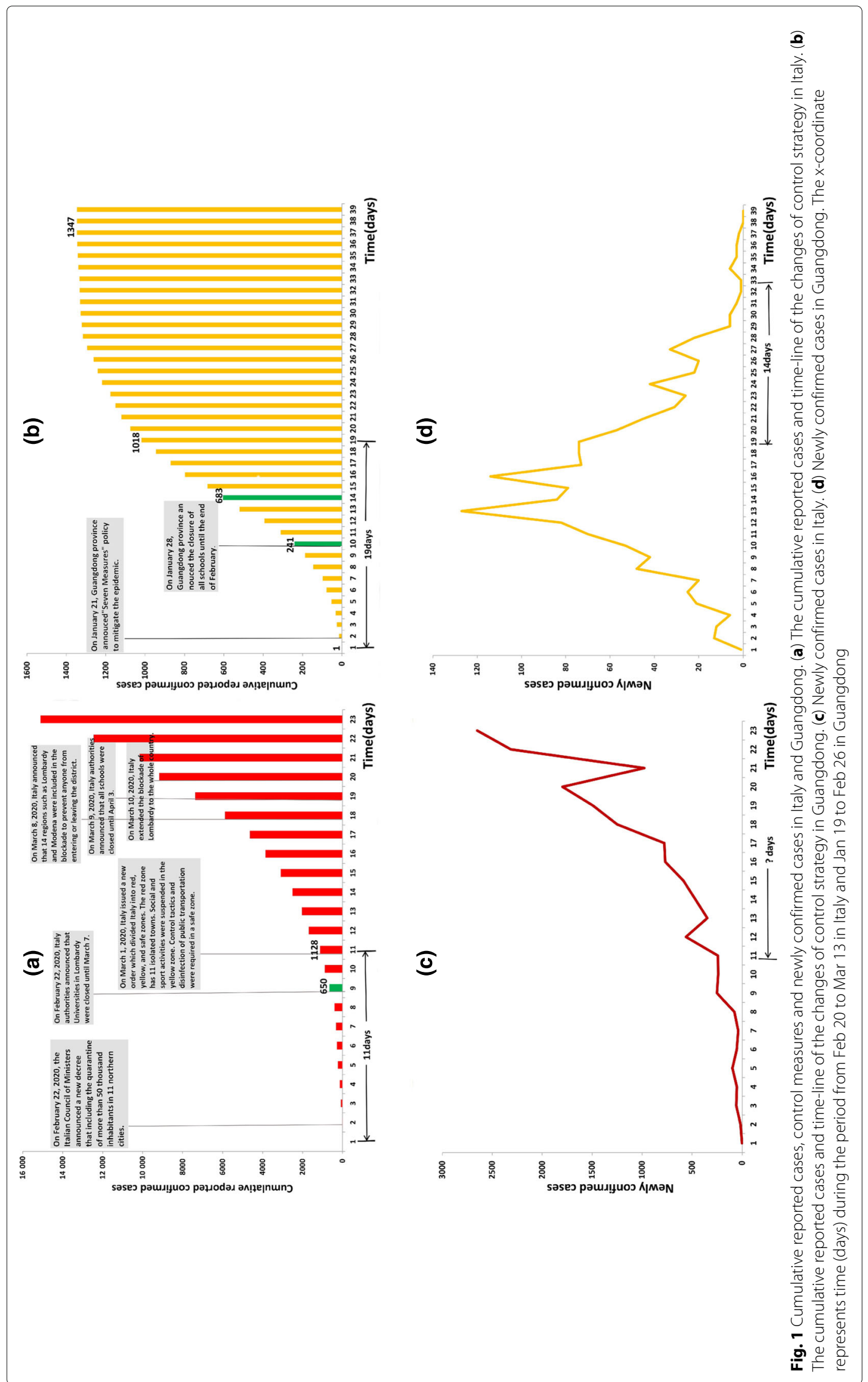


(e.g. blockade of unnecessary public places) on the third day (January 21) to prevent the spread of the epidemic and shut down all schools on January 28, when there were only 241 cumulative confirmed cases (Fig. 1b). Therefore, Italy closed schools about 5 days (January 28 - February 2) later than Guangdong. In Fig. 1c we see that the number of cumulative cases has already exceeded 10 thousand in Italy, however, the newly confirmed cases in Guangdong began to decline since the 37th day and reached the peak of cumulative cases at only 1347 (Fig. 1d). In summary, it took 14 days for Guangdong's reported cases to decline since its cumulative confirmed cases exceeded 1000.

\section{Model}

In the early stage of the epidemic in Italy, the government did not take many prevention measures across the country. Thus, to study the epidemic of this stage, we extend the classical deterministic susceptible-exposedinfectious-removed (SEIR) epidemic model by dividing the population into susceptible $(S)$, exposed $(E)$, symptomatic/asymptomatic infected $(I / A)$, confirmed $(H)$ and recovered $(R)$ compartments. The susceptible and exposed populations are further partitioned into quarantined susceptible $\left(S_{q}\right)$ and quarantined suspected individuals $\left(E_{q}\right)$. Based on the previous research [22], we adopt an autonomous model to study the early stage of the outbreak. We assume that the individuals exposed to the virus are quarantined with a proportion $q$ by contact tracing. If the quarantined individuals are successfully infected, they will move to $E_{q}$ compartment, otherwise they move to the $S_{q}$ compartment. The individuals who exposed to the virus but were missed in the contact tracing with rate $1-q$ can either move to the compartment $E$ or still stay in compartment $S$, depending on whether they are infected or not. We assume that the successful transmission probability is $\beta$ and the contact rate is c. The infected individuals can be detected and then isolated at a rate of $\delta_{I}$ or move to the compartment $R$ at the rate of $\gamma_{I}$ due to recovery. The death rate of the infectious individuals with symptoms $I$ and the isolated infected individuals $H$ is $\alpha$. We also assume that the asymptomatic infectious is neither dead nor hospitalized. With these assumptions the model can be described by

$$
\begin{aligned}
& \frac{d S}{d t}=-(\beta c+c q(1-\beta)) S \frac{(I+\theta A)}{N}+\lambda S_{q}, \\
& \frac{d E}{d t}=\beta c(1-q) S \frac{(I+\theta A)}{N}-\sigma E, \\
& \frac{d I}{d t}=\sigma \rho E-\left(\delta_{I}+\alpha+\gamma_{I}\right) I, \\
& \frac{d A}{d t}=\sigma(1-\rho) E-\gamma_{A} A, \\
& \frac{d S_{q}}{d t}=(1-\beta) c q S \frac{(I+\theta A)}{N}-\lambda S_{q}, \\
& \frac{d E_{q}}{d t}=\beta c q S \frac{(I+\theta A)}{N}-\delta_{q} E_{q}, \\
& \frac{d H}{d t}=\delta_{I} I+\delta_{q} E_{q}-\left(\alpha+\gamma_{H}\right) H, \\
& \frac{d R}{d t}=\gamma_{I} I+\gamma_{A} A+\gamma_{H} H .
\end{aligned}
$$

The more detailed definitions of variables and parameters for model (1) are provided in Table 1. As the population size is much larger than the size of the outbreak, i.e. $S(t) / N \approx 1$, the basic reproductive number $R_{0}$ of model (1) is given by the following formula by utilizing the next generation matrix [32].

$$
R_{0}=\frac{\beta \rho c(1-q)}{\delta_{I}+\alpha+\gamma_{I}}+\frac{\beta(1-\rho) c \theta(1-q)}{\gamma_{A}} .
$$

\section{Time-dependent model}

The above model will be used to study the early stage of the outbreak. However, with a series of prevention and control measures being implemented by the government, the autonomous model needs to be modified. Because of the difference before and after the implementation of control measures, piecewise functions of the contact rate and diagnosis rate are introduced to the autonomous model.

The contact rate is a constant in the autonomous model, i.e. the average number of susceptible individuals that an exposed people can contact without any control measures in a unit time. As the action of regional or national lockdown came into effect, people's contact will gradually decrease. Thus, we assume that the contact rate is an exponential decreasing function of time $t$ after the government has taken the control measures. The contact rate $c(t)$ is assumed to take the following form:

$$
c(t)=\left\{\begin{array}{l}
c_{0}, t \leq t^{*}+\tau, \\
\left(c_{0}-c_{b}\right) e^{-r_{1}\left(t-t^{*}-\tau\right)}+c_{b}, t>t^{*}+\tau .
\end{array}\right.
$$

Here $c_{0}$ denotes the contact rate at the initial time without control measures, $c_{b}$ denotes the minimum contact rate under the current control strategies $\left(c_{b}<c_{0}\right)$. Clearly, $c(0)=c_{0}, \lim _{t \rightarrow \infty} c(t)=c_{b}$. The parameter $r_{1}$ in the exponential decreasing rate $c(t)$ measures how fast the contact rate decreases under control measures. The data we used for fitting started from February 20, 2020 and Italy was blockaded on March 10, 2020. Thus, we let $t^{*}=18$. Since the control measures cannot come into effect immediately after the implementation, we add a time lag $\tau$ which represents the delayed effect of prevention actions (the earlier and stricter the implementation actions, the smaller the $\tau)$.

Similarly, because the efficiency of detection and availability of medical resources vary, we assume that the diagnosis rate is a time-dependent piecewise function rather than a constant. It is an increasing function when medical resources are adequate and a decrease function when they are not. The duration of diagnosis $1 / \delta_{I}(t)$ is given by the following form:

$$
\frac{1}{\delta_{I}(t)}=\left\{\begin{array}{l}
\frac{1}{\delta_{I 0}}, t \leq t^{*}, \\
\left(\frac{1}{\delta_{I 0}}-\frac{1}{\delta_{I f}}\right) e^{-r_{2}\left(t-t^{*}\right)}+\frac{1}{\delta_{I f}}, t>t^{*},
\end{array}\right.
$$


Table 1 Estimates of parameters and initial values of variables in model (1)

\begin{tabular}{|c|c|c|c|}
\hline Parameters & Definition & value & Source \\
\hline c & Initial contact rate & 15 & Estimated \\
\hline$\beta$ & $\begin{array}{l}\text { Probability of successful } \\
\text { transmission }\end{array}$ & 0.1334 & Estimated \\
\hline$\theta$ & $\begin{array}{l}\text { Transmission probability } \\
\text { reduction of } \\
\text { asymptomatically infected } \\
\text { individuals }\end{array}$ & 0.1 & Estimated \\
\hline$\rho$ & $\begin{array}{l}\text { Ratio of symptomatic } \\
\text { infection }\end{array}$ & 0.6 & Estimated \\
\hline 9 & $\begin{array}{l}\text { Quarantine rate of } \\
\text { exposed individuals }\end{array}$ & 0.415 & Estimated \\
\hline$\sigma$ & $\begin{array}{l}\text { Transition rate of exposed } \\
\text { individuals to the infected } \\
\text { class }\end{array}$ & $1 / 7$ & [33] \\
\hline$\lambda$ & $\begin{array}{l}\text { Rate at which the quaran- } \\
\text { tined uninfected contacts } \\
\text { are released }\end{array}$ & $1 / 14$ & [22] \\
\hline$\delta_{l}$ & $\begin{array}{l}\text { Transition rate of } \\
\text { symptomatically infected } \\
\text { individuals to the } \\
\text { quarantined infected class }\end{array}$ & 0.2257 & Estimated \\
\hline$\delta_{q}$ & $\begin{array}{l}\text { Transition rate of } \\
\text { quarantined exposed } \\
\text { individuals to the } \\
\text { quarantined infected class }\end{array}$ & 0.2 & Estimated \\
\hline$\gamma_{l}$ & $\begin{array}{l}\text { Recovery rate of } \\
\text { symptomatically infected } \\
\text { individuals }\end{array}$ & 0.02 & Estimated \\
\hline$\gamma_{A}$ & $\begin{array}{l}\text { Recovery rate of } \\
\text { asymptomatically infected } \\
\text { individuals }\end{array}$ & 0.07 & Estimated \\
\hline$\gamma_{H}$ & $\begin{array}{l}\text { Recovery rate of } \\
\text { quarantined infected } \\
\text { individuals }\end{array}$ & 0.0239 & Estimated \\
\hline$\alpha$ & $\begin{array}{l}\text { Disease-induced death } \\
\text { rate }\end{array}$ & 0.013 & Estimated \\
\hline$N$ & The total population & $6.048 \times 10^{7}$ & Data \\
\hline$E(0)$ & Initial exposed population & 26 & Estimated \\
\hline$I(0)$ & $\begin{array}{l}\text { Initial symptomatically } \\
\text { infected population }\end{array}$ & 20 & Estimated \\
\hline$A(0)$ & $\begin{array}{l}\text { Initial asymptomatically } \\
\text { infected population }\end{array}$ & 5 & Estimated \\
\hline$S_{q}(0)$ & $\begin{array}{l}\text { Initial quarantined } \\
\text { susceptible population }\end{array}$ & 51 & Estimated \\
\hline$E_{q}(0)$ & $\begin{array}{l}\text { Initial quarantined } \\
\text { exposed population }\end{array}$ & 13 & Estimated \\
\hline$H(0)$ & $\begin{array}{l}\text { Initial quarantined } \\
\text { infected population }\end{array}$ & 3 & Data \\
\hline$R(0)$ & $\begin{array}{l}\text { Initial recovered } \\
\text { population }\end{array}$ & 0 & Data \\
\hline
\end{tabular}

where $\delta_{I 0}$ is the diagnosis rate at the initial time. If the efficiency of detection is increasing with time $t$, then the diagnosis rate $\delta_{I}(t)$ will increase. The parameter $r_{2}$ measures how fast the diagnosis rate increases (i.e. the duration of diagnosis decreases) as more medical equipments or resources become available. The final diagnosis rate $\delta_{I f}$ is usually larger than $\delta_{I 0}$. However, if the medical resource is inadequate, the diagnosis rate $\delta_{I}(t)$ can decrease and the final diagnosis rate $\delta_{I f}$ can be less than $\delta_{I 0}$.

According to the basic reproductive number $R_{0}$, timevarying contact rate Eq. (2) and diagnosis rate Eq. (3), the effective reproductive number $R_{c}(t)$ of time-dependent model is given by the following formula:

$$
R_{c}(t)=\frac{\beta \rho c(t)(1-q)}{\delta_{I}(t)+\alpha+\gamma_{I}}+\frac{\beta(1-\rho) c \theta(1-q)}{\gamma_{A}}
$$

Although the government's mandatory intervention plays a major role in epidemic control, people's behavior changes such as keeping social distancing, wearing facial masks and washing hands due to media and expert suggestions cannot be ignored. Hence, the piecewise function similar to the previous contact rate and diagnosis rate is applied to the transmission rate $\beta$. Considering that the impact of behavior change on the spread of the disease is not as great as the government mandatory intervention, the exponential change form is not used. If the number of reported confirmed cases increases, the public will enhance self-protection measures. Thus, we assume that the transmission rate $\beta$ is inversely proportional to reported confirmed cases $H(t)$. The time-dependent transmission rate $\beta(t)$ takes the following form:

$$
\beta(t)=\left\{\begin{array}{l}
\beta_{0}, \text { if } \frac{1}{k \log (H(t))}>1, \\
\beta_{0} \frac{1}{k \log (H(t))}
\end{array}\right.
$$

where $k$ represents the indicator measures strength of people's awareness of self-prevention. The larger the value of $k$, the smaller the transmission rate.

\section{Data fitting with autonomous model}

According to the total population of Italy and the epidemic situation on February 20, 2020, we set initial values to be $S(0)=60480000, H(0)=3$ and $R(0)=0$. According to the WHO [33], the incubation period of COVID-19 is about 7 days. Thus, $\sigma=1 / 7$. The quarantined individuals were quarantined for 14 days, thus $\lambda=1 / 14$. We obtain other unknown parameter values by fitting data on reported number of cumulative confirmed cases, death cases and recovery cases from February 20 to March 10 in Italy. We utilized the nonlinear least-square (NLES) method in Matlab to fit model solution to the real data sets, as shown in Fig. 2. The estimated parameter values are listed in Table 1. 


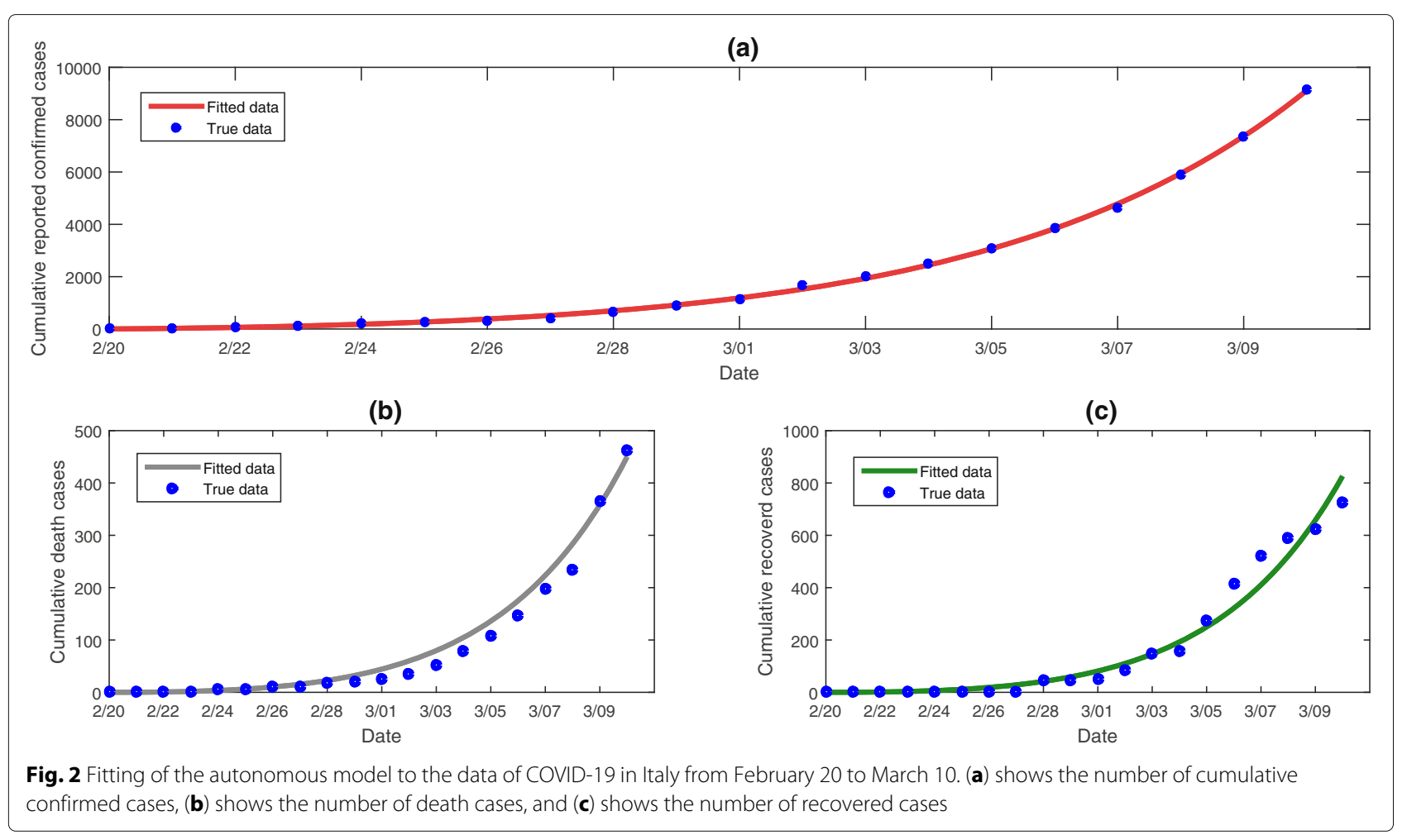

\section{Results and discussion Global epidemics}

The global spread of the epidemic has gone through two stages, as shown in Fig. 3. In the first stage, COVID-19 spread to 22 countries around the world before the end of January. In this stage, there was a huge deficiency of cognition about this new coronavirus. In early February, under severe travel restrictions of a few cities including Wuhan in China and strict quarantine interventions carried out by other provinces, the epidemic did not spread swiftly to more countries and only increased by seven countries in 30 days window period. Nevertheless, in the second phase, it took only 19 days for the number of infected countries to ascend rapidly from 29 on February 22 to 114 in late March. The discrepancy between these two stages is due to the interventions implemented by China and other countries.

\section{Data comparison in Italy and Guangdong}

According to the World Bank Organization, Italy has 60.48 million people while Guangdong has a population of 111.69 million. Thus, there are more susceptible people in Guangdong than in Italy [34]. However, it can be seen from the data of accumulative cases that it took 19 days for Guangdong Province to increase from 1 case to more than 1000 cases, while it took only 11 days for Italy to increase from 4 cases to more than 1000 cases. It illustrates that the prevention and control tactics of Guangdong Province in the early stage of the epidemic is more effective than that of Italy under the condition of similar diagnosis rate.

The ascent and descent of newly confirmed cases are bound up with the prevalence ratio, cure ratio and prevention and control measures in the two places. When other conditions are the same, the higher the prevalence ratio, the higher the cure ratio. The more effective the interventions, the fewer newly diagnosed patients per day. Specifically, in Fig. 4 we utilize the ratio of reported cases to the total population to represent the prevalence ratio. Because the calculated prevalence ratios are very small, we multiply by 10000 for the ease of illustration. Similarly, we use the ratio of recovered cases to cumulative confirmed population to represent the cure ratio. In sum, we select February 20 as Italy's 1st day and February 19 as Guangdong's 1st day, with the $\mathrm{x}$-axis representing days and $y$-axis representing the prevalence ratio or cure ratio. Italian prevalence ratio is much higher than Guangdong's (Fig. 4a). Italy has more than 20 times as many patients as Guangdong, while Guangdong has nearly twice as many susceptible populations as Italy. This means that Italian epidemic state is more serious than Guangdong's. In view of the cure ratio (Fig. 4b), we can see that Guangdong's curve is more smooth than Italy, which means that Guangdong's cure ratio is more stable than Italy's.

The data observation and comparison suggest that the situation of the international epidemic, particularly in Italy, was urgent. Compared with the epidemic situation 


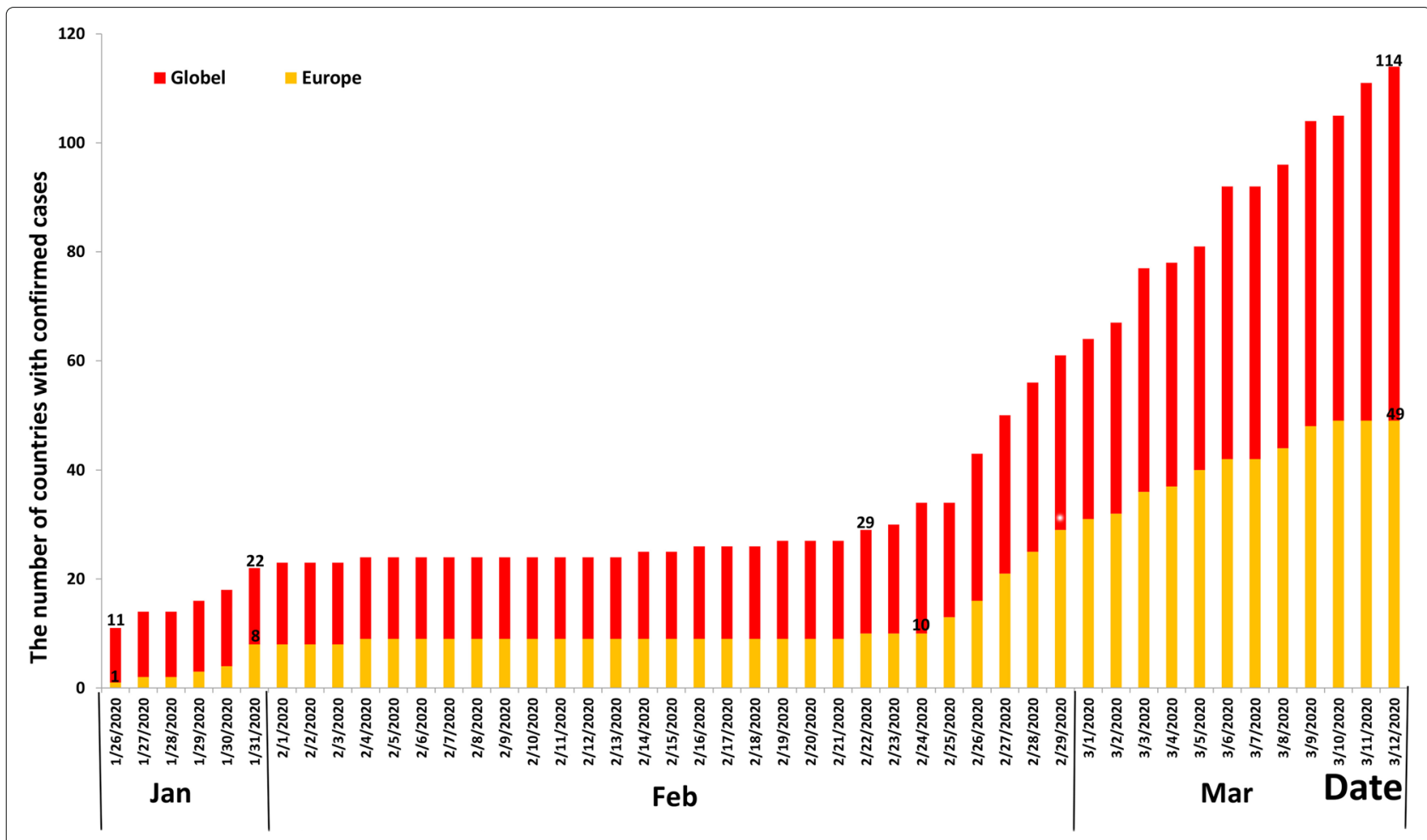

Fig. 3 The epidemics in Europe and the world. The red bar represents the number of countries with confirmed cases in the world. The yellow bar represents the number of countries with confirmed cases in Europe

in Guangdong Province, the situation in Italy is relatively serious due to the lack of timely control measures. Last but not least, the cure ratio curve (Fig. 4b) shows that medical resources would be insufficient in Italy.

\section{Parameter estimation}

In the early stage of the outbreak in Italy, the probability of successful transmission was $13.34 \%(\beta=0.1334)$. There were $40 \%$ asymptomatic infected individuals in infected population and their ability to infect others was $10 \%$ of those with symptoms $(\rho=0.6, \theta=0.1)$. The diseaseinduced death rate among symptomatic was $1.3 \%(\alpha=$ 0.013). Our parameter values are consistent with results in some other publications: the successful infection rate is $12 \%$ in reference [35], the ratio of asymptomatic infections is $56 \%$ in reference [36], and the case-lethal rate among

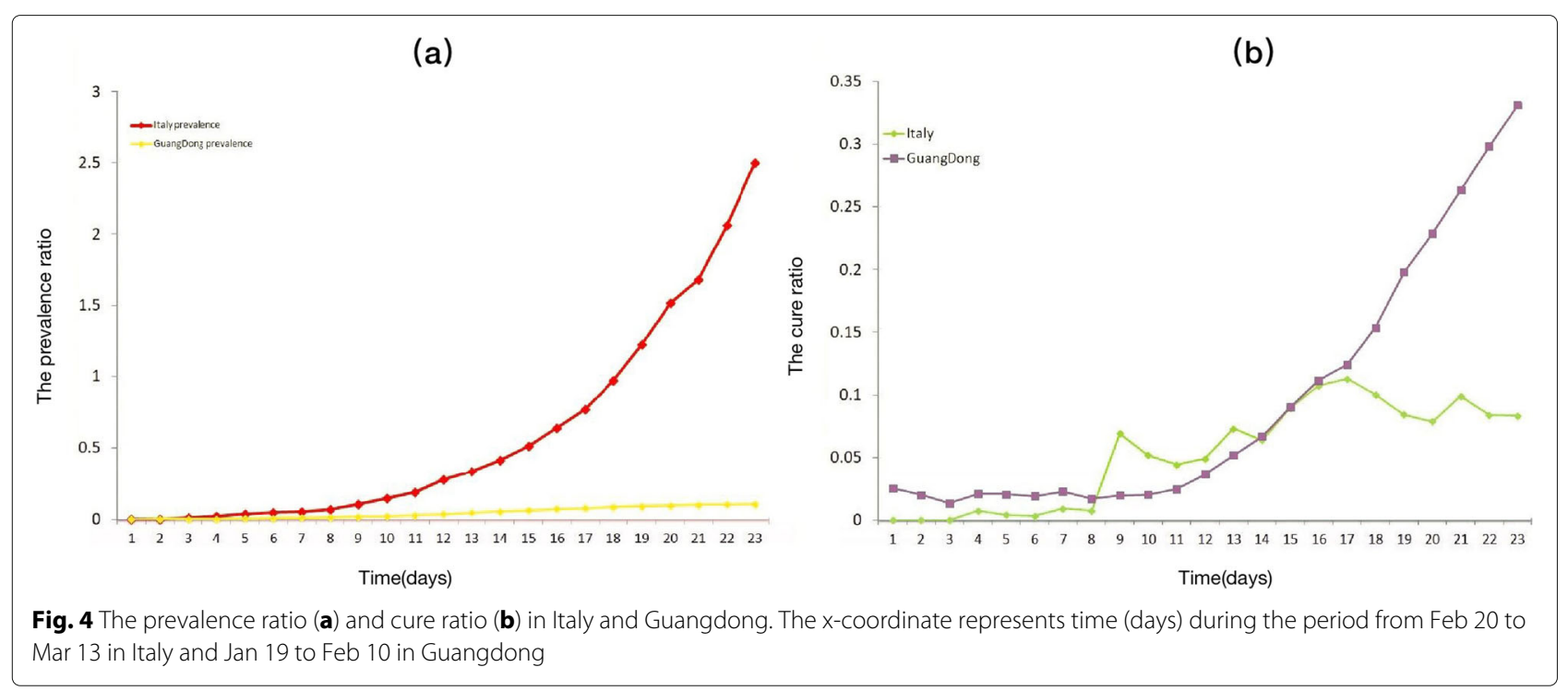



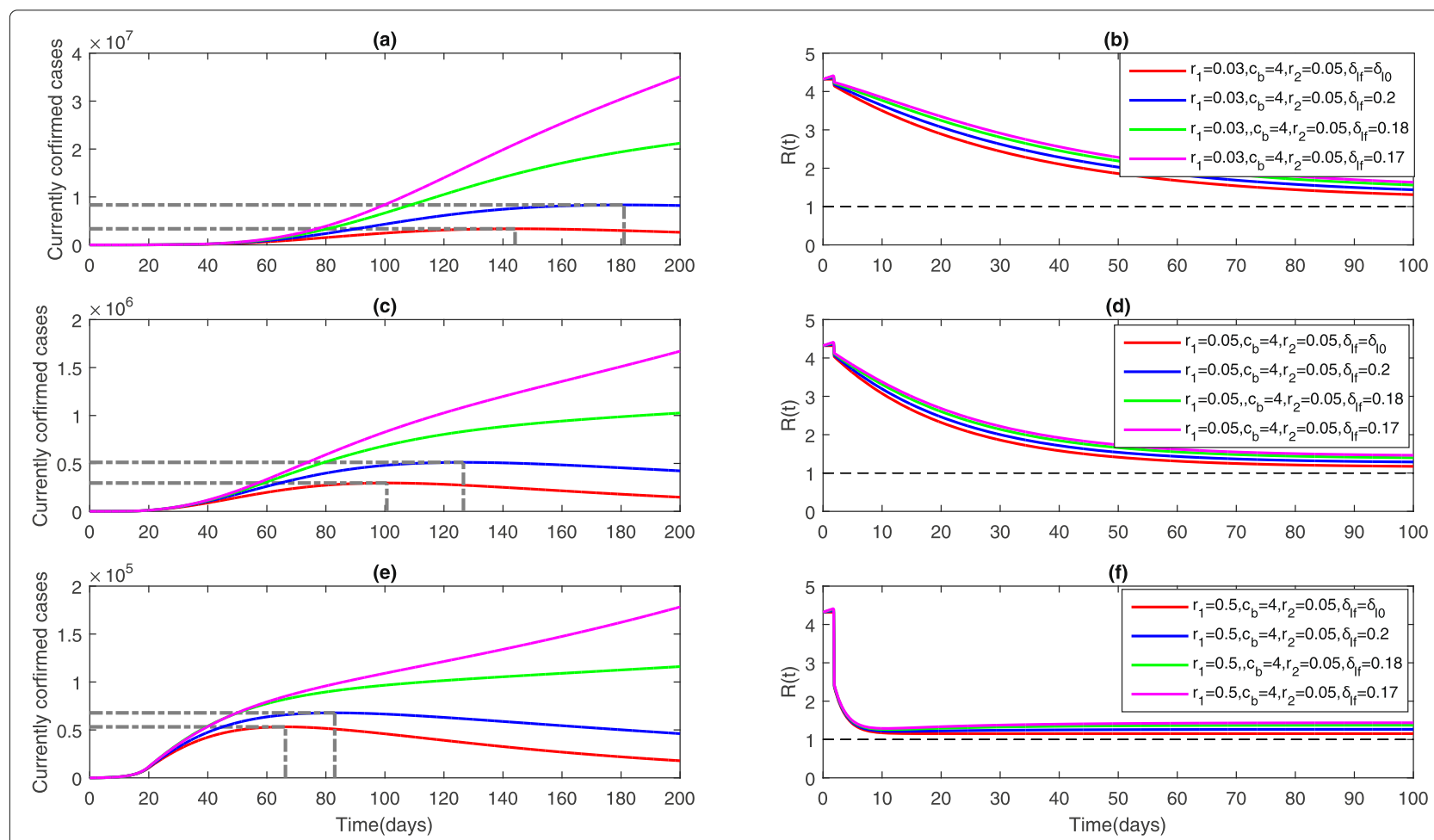

Fig. 5 The prediction of currently confirmed cases (left column) and the effective reproduction number (right column) with different sets of parameter values (see text). The $x$ axis is time (days) of simulation. $(\mathbf{a}-\mathbf{b}) r_{1}=0.03,(\mathbf{c}-\mathbf{d}) r_{1}=0.05,(\mathbf{e}-\mathbf{f}) r_{1}=0.5$. The red, blue, green and magenta lines represent $\delta_{\mid f}=\delta_{10}, \delta_{l f}=0.2, \delta_{\text {If }}=0.18, \delta_{\mid f}=0.17$, respectively
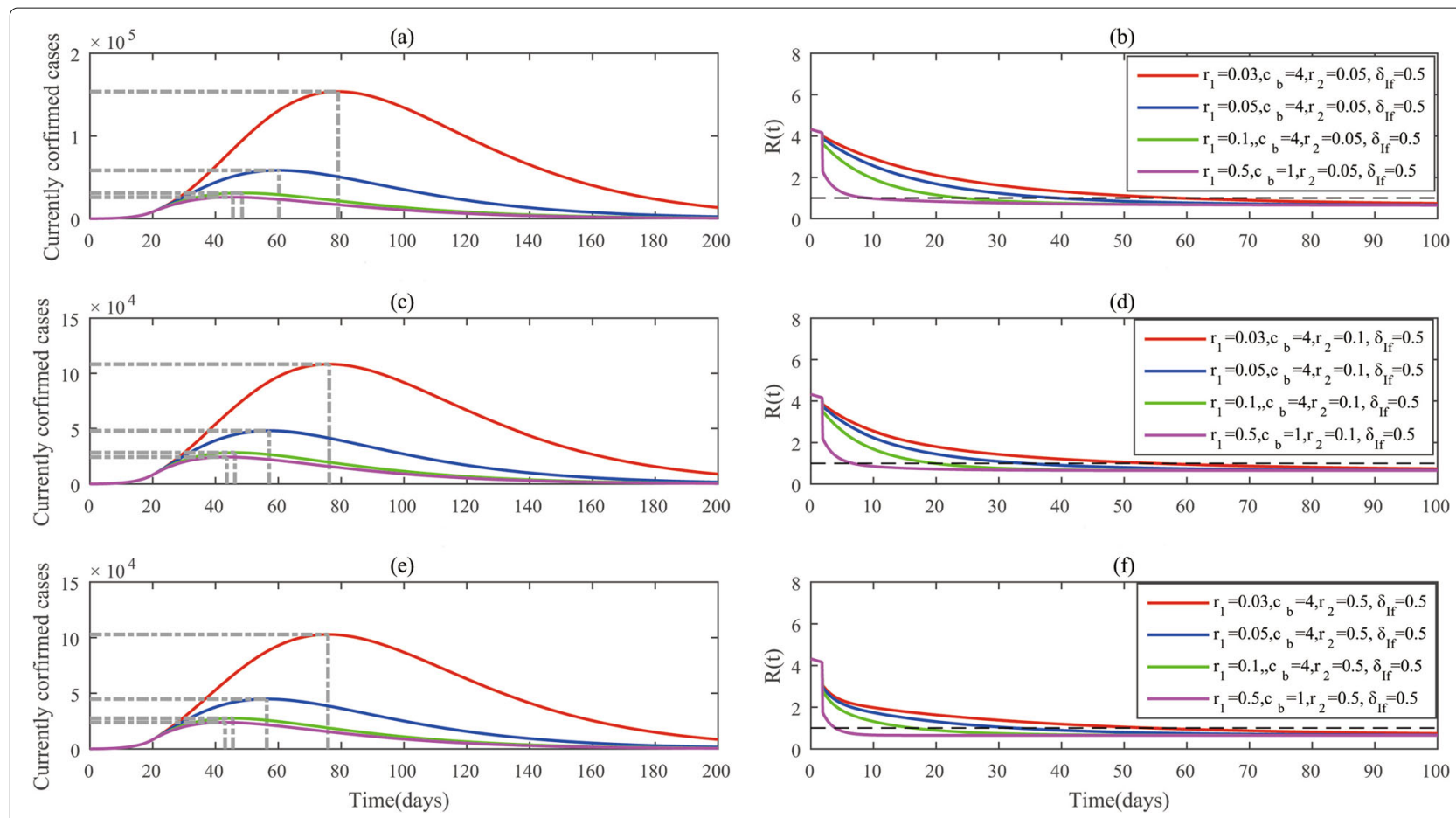

Fig. 6 The prediction of currently confirmed cases (left column) and the effective reproduction number (right column) with different sets of parameter values (see text). The $x$ axis is time (days) of simulation. (a-b) $r_{2}=0.05 ;(\mathbf{c}-\mathbf{d}) r_{2}=0.1,(\mathbf{e}-\mathbf{f}) r_{2}=0.5$. The red, blue, green and magenta line represent $r_{1}=0.03, c_{b}=4, r_{1}=0.05, c_{b}=4, r_{1}=0.1, c_{b}=4, r_{1}=0.5, c_{b}=1$, respectively 
Table 2 Different control measure intensities and prediction results

\begin{tabular}{|c|c|c|c|}
\hline & Parameter assumption & Peak day & Maximum confirmed cases \\
\hline & $\delta_{l f}=0.5, r_{2}=0.05, \tau=0$ & 79 & $1.54 \times 10^{5}$ \\
\hline & $\delta_{\text {lf }}=0.5, r_{2}=0.05, \tau=5$ & 79 & $2.42 \times 10^{5}$ \\
\hline \multirow[t]{15}{*}{$c_{b}=4, r_{1}=0.03$} & $\delta_{l f}=0.5, r_{2}=0.05, \tau=10$ & 80 & $4.00 \times 10^{5}$ \\
\hline & $\delta_{\text {If }}=0.5 r_{2}=0.1 \tau=0$ & 76 & $1.08 \times 10^{5}$ \\
\hline & $\delta_{l f}=0.5 r_{2}=0.1 \tau=5$ & 77 & $1.86 \times 10^{5}$ \\
\hline & $\delta_{\text {lf }}=0.5 r_{2}=0.1 \tau=10$ & 77 & $3.32 \times 10^{5}$ \\
\hline & $\delta_{\text {lf }}=0.5 r_{2}=0.5 \tau=0$ & 76 & $1.03 \times 10^{4}$ \\
\hline & $\delta_{l f}=0.5 r_{2}=0.5 \tau=5$ & 76 & $1.75 \times 10^{5}$ \\
\hline & $\delta_{\text {If }}=0.5 r_{2}=0.5 \tau=10$ & 77 & $3.21 \times 10^{5}$ \\
\hline & $\delta_{\text {If }}=\delta_{10} r_{2}=0.05 \tau=0$ & 144 & $3.36 \times 10^{6}$ \\
\hline & $\delta_{\text {lf }}=\delta_{10} r_{2}=0.05 \tau=5$ & 144 & $5.38 \times 10^{6}$ \\
\hline & $\delta_{l f}=\delta_{10} r_{2}=0.05 \tau=10$ & 144 & $9.31 \times 10^{6}$ \\
\hline & $\delta_{\text {If }}=0.2 r_{2}=0.05 \tau=0$ & 181 & $8.34 \times 10^{6}$ \\
\hline & $\delta_{\text {lf }}=0.2 r_{2}=0.05 \tau=5$ & 181 & $1.29 \times 10^{7}$ \\
\hline & $\delta_{\text {If }}=0.2 r_{2}=0.05 \tau=10$ & 181 & $2.51 \times 10^{7}$ \\
\hline & $\delta_{\text {lf }}=0.5, r_{2}=0.05 \tau=0$ & 60 & $5.85 \times 10^{4}$ \\
\hline & $\delta_{\text {lf }}=0.5, r_{2}=0.05 \tau=5$ & 61 & $1.05 \times 10^{5}$ \\
\hline \multirow[t]{13}{*}{$c_{b}=4, r_{1}=0.05$} & $\delta_{\mid f}=0.5, r_{2}=0.05 \tau=10$ & 63 & $1.99 \times 10^{5}$ \\
\hline & $\delta_{l f}=0.5 r_{2}=0.1 \tau=0$ & 57 & $4.81 \times 10^{4}$ \\
\hline & $\delta_{l f}=0.5 r_{2}=0.1 \tau=5$ & 59 & $4.81 \times 10^{4}$ \\
\hline & $\delta_{\text {lf }}=0.5 r_{2}=0.1 \tau=10$ & 61 & $8.79 \times 10^{4}$ \\
\hline & $\delta_{\text {lf }}=0.5 r_{2}=0.5 \tau=0$ & 56 & $1.81 \times 10^{5}$ \\
\hline & $\delta_{l f}=\delta_{10} r_{2}=0.05 \tau=0$ & 101 & $2.96 \times 10^{5}$ \\
\hline & $\delta_{\text {If }}=\delta_{10} r_{2}=0.05 \tau=5$ & 101 & $5.77 \times 10^{5}$ \\
\hline & $\delta_{l f}=\delta_{10} r_{2}=0.05 \tau=10$ & 101 & $1.21 \times 10^{6}$ \\
\hline & $\delta_{\text {If }}=0.2 r_{2}=0.05 \tau=0$ & 127 & $5.11 \times 10^{5}$ \\
\hline & $\delta_{\text {lf }}=0.2 r_{2}=0.05 \tau=5$ & 127 & $9.82 \times 10^{5}$ \\
\hline & $\delta_{\text {lf }}=0.2 r_{2}=0.05 \tau=10$ & 127 & $2.07 \times 10^{6}$ \\
\hline & $\delta_{l f}=0.5, r_{2}=0.05 \tau=0$ & 48 & $3.12 \times 10^{4}$ \\
\hline & $\delta_{\text {If }}=0.5, r_{2}=0.05 \tau=5$ & 52 & $6.69 \times 10^{4}$ \\
\hline \multirow[t]{15}{*}{$c_{b}=4, r_{1}=0.1$} & $\delta_{l f}=0.5, r_{2}=0.05 \tau=10$ & 55 & $1.41 \times 10^{5}$ \\
\hline & $\delta_{\mid f}=0.5 r_{2}=0.1 \tau=0$ & 46 & $2.85 \times 10^{4}$ \\
\hline & $\delta_{l f}=0.5 r_{2}=0.1 \tau=5$ & 50 & $6.26 \times 10^{4}$ \\
\hline & $\delta_{\text {If }}=0.5 r_{2}=0.1 \tau=10$ & 54 & $1.35 \times 10^{5}$ \\
\hline & $\delta_{l f}=0.5 r_{2}=0.5 \tau=0$ & 46 & $2.75 \times 10^{4}$ \\
\hline & $\delta_{\text {lf }}=0.5 r_{2}=0.5 \tau=5$ & 49 & $6.15 \times 10^{4}$ \\
\hline & $\delta_{\text {lf }}=0.5 r_{2}=0.5 \tau=10$ & 54 & $1.33 \times 10^{5}$ \\
\hline & $\delta_{l f}=\delta_{10} r_{2}=0.05 \tau=0$ & 66 & $5.32 \times 10^{4}$ \\
\hline & $\delta_{\text {If }}=\delta_{10} r_{2}=0.05 \tau=5$ & 71 & $1.56 \times 10^{5}$ \\
\hline & $\delta_{l f}=\delta_{10} r_{2}=0.05 \tau=10$ & 76 & $4.64 \times 10^{5}$ \\
\hline & $\delta_{\text {lf }}=0.2 r_{2}=0.05 \tau=0$ & 83 & $6.78 \times 10^{4}$ \\
\hline & $\delta_{\text {lf }}=0.2 r_{2}=0.05 \tau=5$ & 88 & $2.07 \times 10^{5}$ \\
\hline & $\delta_{\text {lf }}=0.2 r_{2}=0.05 \tau=10$ & 89 & $6.10 \times 10^{5}$ \\
\hline & $\delta_{\text {lf }}=0.5, r_{2}=0.05 \tau=0$ & 46 & $2.61 \times 10^{4}$ \\
\hline & $\delta_{\text {lf }}=0.5, r_{2}=0.05 \tau=5$ & 50 & $6.00 \times 10^{4}$ \\
\hline \multirow[t]{7}{*}{$c_{b}=1, r_{1}=0.5$} & $\delta_{\mid f}=0.5, r_{2}=0.05 \tau=10$ & 54 & $1.34 \times 10^{5}$ \\
\hline & $\delta_{\text {lf }}=0.5 r_{2}=0.1 \tau=0$ & 44 & $2.45 \times 10^{4}$ \\
\hline & $\delta_{l f}=0.5 r_{2}=0.1 \tau=5$ & 48 & $5.69 \times 10^{4}$ \\
\hline & $\delta_{\text {lf }}=0.5 r_{2}=0.1 \tau=10$ & 53 & $1.28 \times 10^{5}$ \\
\hline & $\delta_{l f}=0.5 r_{2}=0.5 \tau=0$ & 43 & $2.39 \times 10^{4}$ \\
\hline & $\delta_{l f}=0.5 r_{2}=0.5 \tau=5$ & 48 & $5.60 \times 10^{4}$ \\
\hline & $\delta_{\text {lf }}=0.5 r_{2}=0.5 \tau=10$ & 53 & $1.27 \times 10^{5}$ \\
\hline
\end{tabular}


symptomatic is $1.29 \%$ in Italy and $1.3 \%$ in New York in references $[37,38]$. The initial contact rate $c$ was 15 in Italy and 10 in Guangdong, China [8]. This also verified our data comparison analysis that the prevention and control measures implemented in Italy were not sufficiently timely and effective comparing with Guangdong.

According to the estimated values of parameters and the formula of the basic reproductive number, the values of $R_{0}$ is 4.3211. It's close to the result of another publication $\left(R_{0}=4.10\right.$ in Italy) [40]. The basic reproduction number of COVID-19 is higher than that for influenza $(1.4-1.6)$ [39] and in comparison with the values of SARS epidemics $\left(R_{0}=4.91\right)$ in Beijing in 2003 [41] and MERS $\left(R_{0}=3.5-\right.$ 6.7) in Jeddah in 2014 [42].

\section{Uncertainty and sensitive analyses}

To examine the possible impact of enhanced interventions on COVID-19 epidemic in Italy, using parameter estimates we plotted the predicted current number of confirmed cases with varying parameters related to the time-dependent contact rate $c(t)$ and diagnosis rate $\delta_{I}(t)$ including $\tau, c_{b}, r_{1}, \delta_{I f}, r_{2}$ in the model with timedependent parameters.

The effect of time lag $\tau$ in the contact rate $c(t)$ on the epidemic of COVID-19 is shown in Table 1 . We can see that the estimated peak value of the number of current confirmed cases significantly increases and the peak time delays $0-\tau$ days as time lag increases. Earlier and stricter lockdown implementation leads to earlier peak time and much lower peak value. For instance, under the control condition $c_{b}=4, r_{1}=0.03, \delta_{I f}=0.5, r_{2}=$ 0.05 , the number of maximum infected cases is $2.42 \times$ $10^{5}$ when $\tau=5$. When $\tau=10$, the peak value is $4.00 \times 10^{5}$, which means that confirmed cases increase by $65 \%$ when the time lag increases by 5 days. This suggests that the earlier and stricter the blockade, the better the control effect.

Figures 5 and 6 show changes of the disease dynamics when the diagnosis rate $\delta_{I}(t)$ is an increasing function and a decreasing function, respectively. There

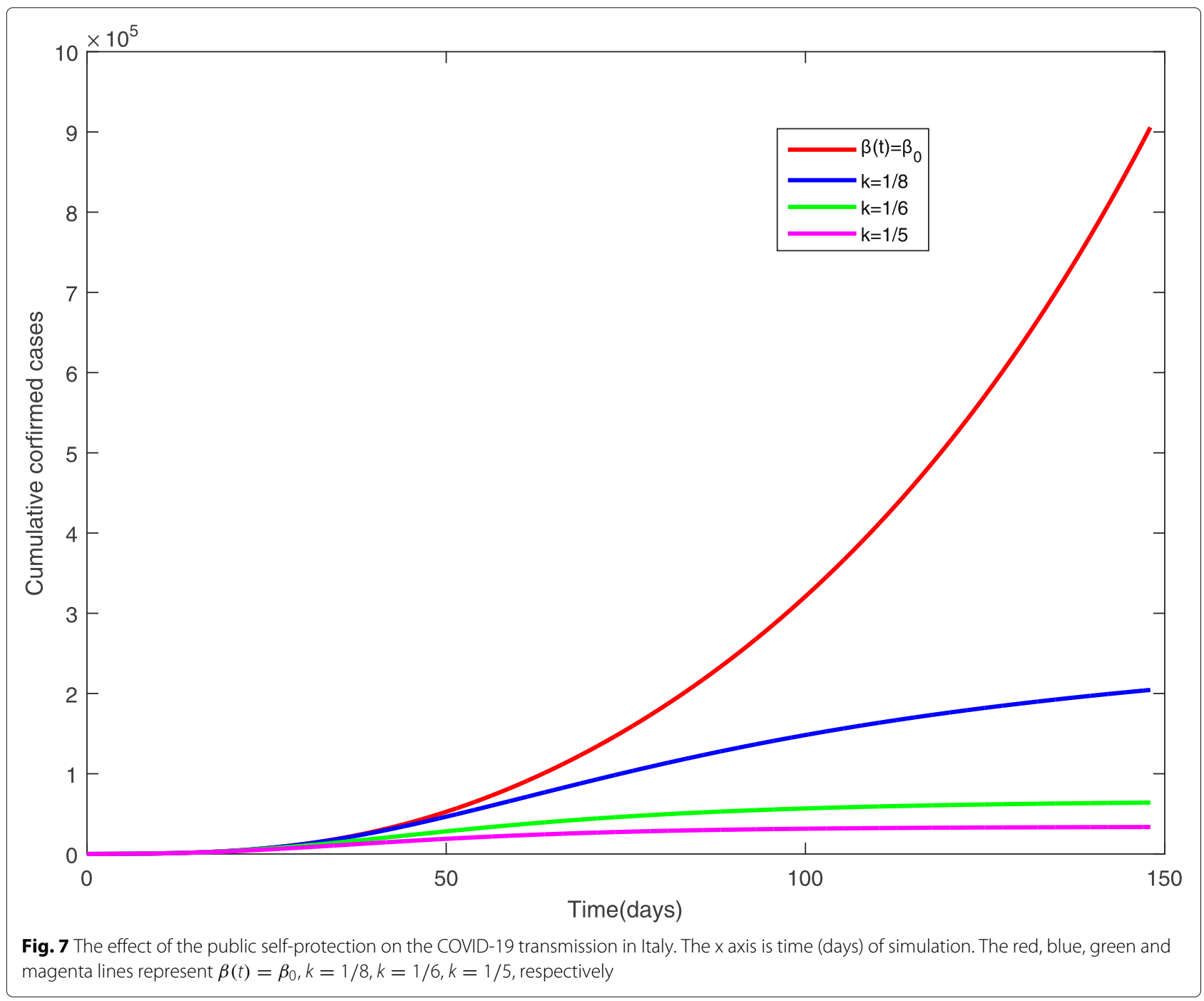


are in total 72 sets of parameter values, representing the variation in the intensity of the control measures implemented.

Figures of the same color in Fig. 5a, c and e show that improving the efficiency of infection detection can largely affect the spread of the infection. The simulations with four different colors in Fig. 5a, c and e show that when the exponential decreasing rate in the contact rate increases, the number of confirmed cases will decrease and the epidemic will peak earlier. For example, under the control conditions $c_{b}=4, \delta_{I f}=0.5, r_{2}=0.05, \tau=0$, the estimated accumulated peak value of confirmed cases decreases by $93 \%\left(3.36 \times 10^{6}-2.96 \times 10^{5}\right)$ when the exponential decreasing rate $r_{1}$ increases by $67 \%(0.03-0.05)$. In addition, the effective reproduction number $R(t)$ will decrease eventually to less than 1 as the control intensities increase, see Fig. 5b, d and f. Therefore, the stronger the control intensity, the faster the infection goes extinct.

During the outbreak of COVID-19, the number of infections rises, leading to the shortage of medical resources. The detection rate may be smaller. We use $\delta_{I f} \leq \delta_{I 0}$ to describe this situation in which $\delta_{I}(t)$ decreases. The magenta and green curves in Fig. 6a, c and e show that the maximum level of the infection will increase when the minimum diagnosis rate is 0.18 or 0.17 . If the minimum diagnosis rate is 0.2 or the diagnosis rate does not increase, the blue and red curves in Fig. 6a, c and e show that the number of confirmed cases is much higher than that in Fig. 5 because of shortage in medical resources. The detailed predicted results of the time when the infection reaches the peak and the maximum number of confirmed cases under different parameter sets are shown in Table 2. These simulations suggest that the effects of prevention and control strategies on epidemic variation are important and huge.

As shown in Fig. 7, we evaluate population's response to the outbreak at four different levels by setting $k=$ $1 / 8,1 / 6,1 / 5$ in Eq. (4) and $\beta(t)=\beta_{0}$. The values of other parameters are the same as those in Table 1 . The red curve shows that the cumulative confirmed cases will keep rising and increasing the parameter $k$ clearly reduce the number of cumulative confirmed cases and can be effective in slowing the overall disease progression trend. This indicates that media news coverage on the status of disease could help improve people's self-protection awareness, leading to a better control of the disease outbreak.

Under different parameter settings, we made predictions of the peak time and cases based on the data from February 20 to March 10. The data in later time show that on April 20th the number of current confirmed cases in Italy peaked at 108237 . This is close to one of our predictions: the number of current confirmed cases reaches the peak value 127000 and the peak time is 53 days (i.e., April 26). Furthermore, using the parameters values in Table 2 , we estimated the parameters in the time-dependent model and fit the cumulative reported cases of Italy by the NLES method (Fig. 8). We obtain the parameter estimates $c_{b}=2.252, r_{1}=0.0242, \delta_{I f}=0.2257, r_{2}=0.0189, \tau=$

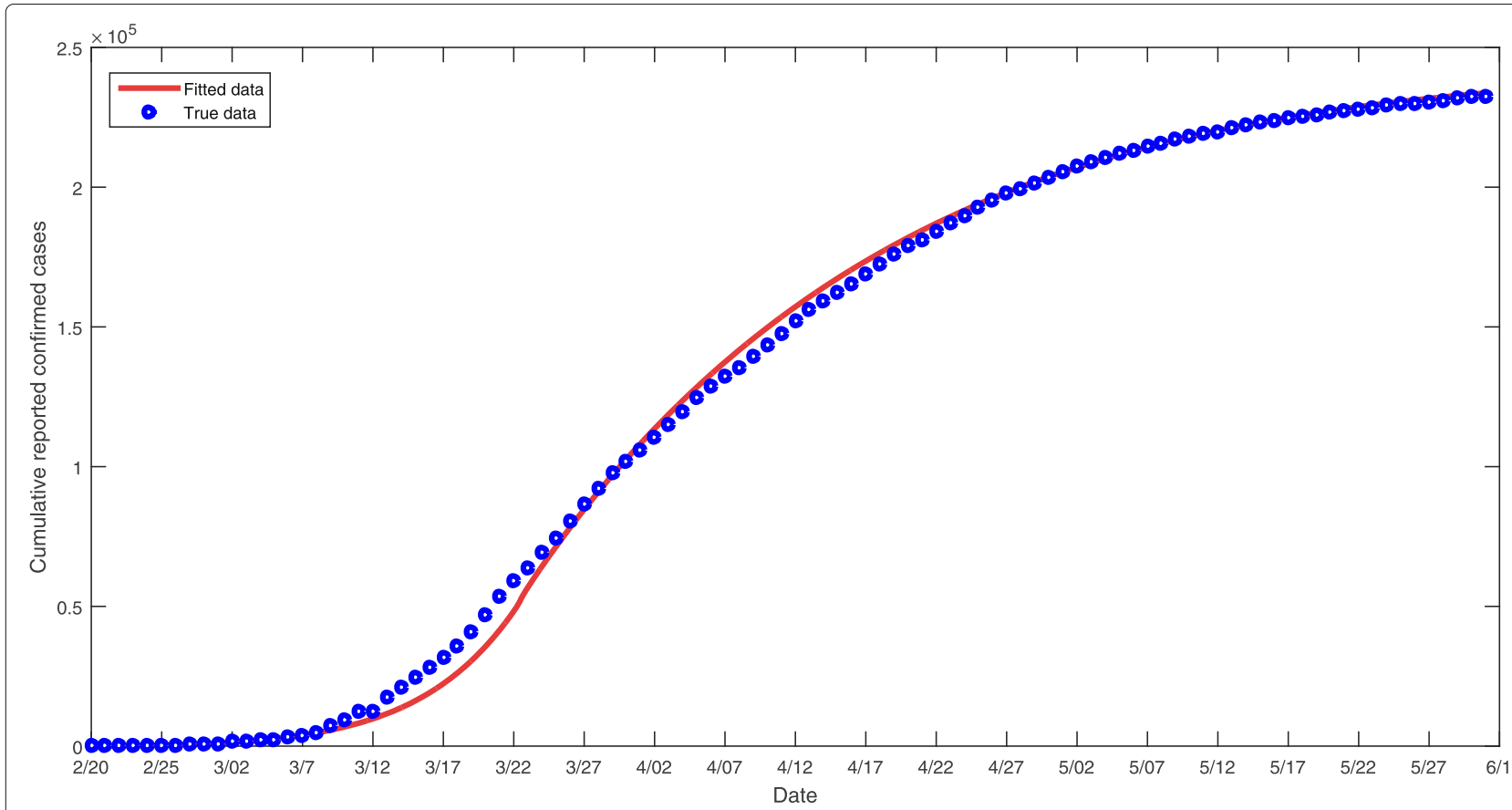

Fig. 8 Fitting of the time-dependent model to very recent data on the cumulative confirmed cases from February 31 to May 31 . The blue points are data and the red line is the fitting result 
12.35. The estimation results show that the decrease in the contact rate is very large, suggesting that Italian recent control measures have played a great role in disease control. The value of the minimum contact rate indicates the strictness of social distancing control and the value of the diagnosis rate determines whether medical resources are sufficient.

\section{Conclusions}

Italy had a very serious epidemic situation before the national lockdown (i.e., March 10), with the basic reproduction number was 4.32. The control measures at that time, including the blockade of schools and medical support, were not sufficiently timely and effectively. Non-pharmaceutical compulsory interventions including contact restrictions (e.g., blockade and quarantine) and improvement of case recognition (i.e., diagnosis rate) play an important role in containing the COVID-19 epidemic. Besides, the effect of individuals behavior change (e.g., keeping social distancing and wearing masks) due to media coverage of the dynamic situation of the epidemic cannot be ignored.

It follows from the data observation and analyses that Italy closed schools at least five days later than Guangdong and the prevalence ratio in Italy is more than 20 times as Guangdong although Italy has fewer susceptible people. The cure ratio curve reveals that there is also a shortage of medical equipments and resources in Italy. Besides, from the global epidemics situation analysis China's timely lockdown of Wuhan city had provided about 30-day window period, during which (from January 24 to February 22) there were only 7 newly infected countries.

The key parameters including delayed effect of prevention actions $\tau$, the exponential decreasing rate of contact rate $r_{1}$, the final diagnosis rate $\delta_{I f}$, the individual behaviour change constant $k$ could significantly affect the outbreak of epidemic COVID-19. In particular, when the estimated peak value of infected cases was controlled at around 108350 (i.e., $c_{b}=4, r_{1}=0.03, \delta_{I f}=0.5, r_{2}=0.1, \tau=0$ ), it increased by $72 \%(108350-186420)$ if the delayed effect of prevention actions $\tau$ increases by 5 days; or decreased by $56 \%(108350-48068)$ if the exponential decreasing rate of contact rate $r_{1}$ increased to 0.05 ; or decreased by $39 \%(108350-66080)$ if the final diagnosis rate $\delta_{\text {If }}$ increased by $16 \%$.

This study presents a novel methodology through using data analysis and embedding the piecewise continuous function of contact rate, diagnosis rate and individual behavior changes (media reports impact) into the autonomous SEIR-type model, showed that combining data analysis with a mathematical model are beneficial for describing the dynamics of the epidemic from the early stage and quantifying the specific effect of nonpharmaceutical measures including lockdown, medical support and media reports on COVID-19. It demonstrated that these control measures affect the accumulated number of hospital notifications by reducing the contact rate (increasing the exponential decreasing rate of contact rate) and the transmission rate (increasing the individual behaviour change constant), and also increasing the diagnosis rate. All these results confirmed the crucial role of governments in implementing early and strict blockade measures and in reducing detection time, and the importance of the media publicity to improve the public awareness of self-protection. Therefore, for mitigating COVID19 epidemic, it is recommended that enforcing isolation and blockade orders, strengthen the supplement of medical resources, and improving the public self-protection awareness should be implemented timely and effectively.

\section{Acknowledgements}

Not applicable.

\section{Authors' contributions}

Conceptualization: S.T.; methodology: S.T.; software: S.H. and P.L.; validation: S.H. and P.L.; formal analysis: P.L. and S.H.; investigation: P.L. and S.H.; resources: P.L. and S.H.; data curation: P.L. and S.H.; writing (original draft preparation): P.L. and S.H.; writing (review and editing): L.R.; visualization: L.R.; supervision: L.R. and S.T.; project administration: S.T. and L.R.; funding acquisition: S.T. and L.R. All authors read and approved the final manuscript.

\section{Funding}

This research was partially supported by the National Natural Science Foundation of China (grant numbers: 61772017 (ST), 11631012 (ST)) and by the Fundamental Research Funds for the Central Universities (grant numbers: 2018 CBLZ001 (SH), GK201901008 (ST)). L. Rong is supported by the National Science Foundation (grant number: DMS-1758290).

\section{Availability of data and materials}

Not applicable.

Ethics approval and consent to participate

Not applicable.

\section{Consent for publication}

Not applicable.

\section{Competing interests}

The authors declare that they have no competing interests.

\section{Author details}

${ }^{1}$ School of Mathematics and Information Science, Shaanxi Normal University, 710119 Xi'an, PR China. ${ }^{2}$ Department of Mathematics, University of Florida, 32601 Gainesville, USA.

Received: 1 April 2020 Accepted: 22 July 2020

Published online: 16 September 2020

\section{References}

1. Cui J, Li F, Shi ZL. Origin and evolution of pathogenic coronaviruses. Nat Rev Microbiol. 2019;17(3):181-92.

2. Ksiazek T, Erdman D, Goldsmith C, Zaki S, Peret T, Emery S, Tong S, Urbani C, Comer JA, Lim W, et al. A novel coronavirus associated with severe acute respiratory syndrome. N Engl J Med. 2003;348(20):1953-66.

3. Drosten C, Gunther S, Preiser W, Werf S, Brodt H, Becker S, Rabenau H, Panning M, Kolesnikova L, Fouchier RAM, et al. Identification of a novel coronavirus in patients with severe acute respiratory syndrome. N Engl J Med. 2003;348:1967-76. 
4. Peiris J, Lai S, Poon L, Guan Y, Yam L, Lim W, Nicholls J, Yee WKS, Yan WW, Cheung MT, et al. Coronavirus as a possible cause of severe acute respiratory syndrome. Lancet. 2003;361:1319-25.

5. He J, Tao H, Yan Y, Huang SY, Xiao Y. Molecular mechanism of evolution and human infection with SARS-CoV-2. Viruses. 2020;12(4):428.

6. Parry J. China coronavirus: cases surge as official admits human to human transmission. BMJ. 2020;368:m236.

7. Lu H, Stratton C, Tang Y. Outbreak of pneumonia of unknown etiology in Wuhan China: The mystery and miracle. J Med Virol. 2020;92(4):401-2.

8. Wang L, Gao YH, Lou LL, Zhang GJ. The clinical dynamics of 18 cases of COVID-19 outside of Wuhan, China. Eur Respir J. 2020;55(4):2000398.

9. Boldog P, Tekeli T, Vizi Z, Denes A, Bartha FA, Rost G. Risk assessment of novel coronavirus COVID-19 outbreaks outside China. J Clin Med. 2020;9(2):597.

10. World Health Organization. Coronavirus Disease (COVID-19) Dashboard. Geneva. 2020. https://covid19.who.int/. Accessed 31 May 2020.

11. Yuchang Z, Zhien M. A discrete epidemic model for SARS transmission and control in China. Math Comput Model. 2005;40(2004):1491-506.

12. Mcleod R, Brewster J, Gumel A, Slonowsky D. Sensitivity and uncertainty analysis for a SARS model with time-varying inputs and outputs. Math Biosci Eng. 2006;3(3):527-44.

13. XuX, Liu Y, Weiss S, Arnold E, Sarafianos S, Ding J. Molecular model of SARS coronavirus polymerase: implication for function and drug design. Nucleic Acids Res. 2003;31(24):7117-30.

14. Yao Y, Bao L, Deng W, Xu L, Li F, Lv Q, Yu P, Chen T, Xu Y, Zhu H, et al. An animal model of MERS produced by infection of rhesus macaques with MERS coronavirus. J Infect Dis. 2014;209:236-42.

15. Cockrell AS, Yount BL, Scobey T, Jensen K, Douglas M, Beall A, Tang XC Marasco WA, Heise MT, Baric RS. A mouse model for MERS coronavirus-induced acute respiratory distress syndrome. Nat Microbiol. 2016;2:16226

16. Xiao Y, Tang $S$, Wu J. Media impact switching surface during an infectious disease outbreak. Sci Rep. 2015;5:7838.

17. Chen TM, Rui J, Wang QP, Zhao ZY, Cui JA, Yin L. A mathematical model for simulating the phase-based transmissibility of a novel coronavirus. Infect Dis Poverty. 2020;9(1):1-8.

18. Peng $L$, Yang W, Zhang D, Zhuge C, Hong L. Epidemic analysis of COVID-19 in China by dynamical modeling. arXiv. 2020. https://arxiv.org/ abs/2002.06563.

19. Wu JT, Leung K, Leung GM. Nowcasting and forecasting the potential domestic and international spread of the 2019-nCoV outbreak originating in Wuhan, China: a modelling study. Lancet. 2020;395(10225):689-97.

20. Zhao S, Musa S, Lin Q, Ran J, Yang G, Wang W, Lou Y, Yang L, Gao D, He D, et al. Estimating the unreported number of novel coronavirus (2019-nCoV) cases in China in the first half of January 2020 : A data-driven modelling analysis of the early outbreak. J Clin Med. 2020:9(2):388.

21. He S, Tang S, Rong L. A discrete stochastic model of the COVID-19 outbreak: Forecast and control. Mat Biosci Eng. 2020;17(4):2792-804.

22. Tang B, Wang X, Li Q, Bragazzi N, Tang S, Xiao Y, Wu J. Estimation of the transmission risk of the 2019-nCoV and its implication for public health interventions. J Clin Med. 2020;9:462.

23. Tang B, Bragazzi N, Li Q, Tang S, Xiao Y, Wu J. An updated estimation of the risk of transmission of the novel coronavirus (2019-nCov). Infect Dis Model. 2020;5:248-55.

24. Tang B, Xia F, Bragazzi N, Wang X, He S, Sun X, Tang S, Xiao Y, Wu J. Lessons drawn from China and South Korea for managing COVID-19 epidemic: insights from a comparative modeling study. medRxiv. 2020. https://doi.org/10.1101/2020.03.09.20033464.

25. Fang $Y$, Nie Y, Penny M. Transmission of the COVID-19 outbreak and effectiveness of government interventions: A data-driven analysis. J Med Virol. 2020;92(6):645-59.

26. Guangdong Provincial Bureau of Statistics. National accounts, Guangzhou. 2020. http://stats.gd.gov.cn/jdgnsczz/index.html. Accessed 21 June 2020

27. World Bank Organization. Indicator. Washington D.C. 2020. https://data. worldbank.org.cn/indicator. Accessed 21 June 2020.

28. National Health Commission of the People's Republic of China. Reports of epidemic situation. Beijing; 2020. http://www.nhc.gov.cn/xcs/yqtb/list_ gzbd.shtml.

29. Health Commission of Guangdong Province. Epidemic information Guangzhou; 2020. http://wsjkw.gd.gov.cn/zwyw_yqxx/index.html. Accessed 12 Mar 2020.
30. Ministry of Health of Italy. COVID-19 Case update. Rome; 2020. http:// opendatadpc.maps.arcgis.com/apps/opsdashboard/index.html\#/ b0c68bce2cce478eaac82fe38d4138b1. Accessed 12 Mar 2020.

31. World Health Organization. Coronavirus disease(COVID-19) situation reports. Geneva; 2020. https://www.who.int/emergencies/diseases/ novel-coronavirus-2019/situation-reports/. Accessed 12 Mar 2020.

32. Tang S, Xiao Y, Yang Y, Zhou Y, Wu J, Ma Z. Community-based measures for mitigating the $2009 \mathrm{H} 1 \mathrm{~N} 1$ pandemic in China. PLoS One. 2010;5(6):e10911.

33. World Health Organization. Statement on meeting of the international health regulations(2005) emergency committee regarding the outbreak of novel coronavirus(2019-ncov). Geneva; 2020. https://www.who.int/ news-room/detail/23-012020-statement-on-the-meeting-of-theinternational-health-regulations-(2005)emergency-committeeregarding-the-outbreak-of-novel-coronavirus-(2019-ncov). Accessed 23 Jan 2020.

34. World Bank Organization. Italy. Washington D.C. 2020. https://data. worldbank.org.cn/country/italy?view=chart. Accessed 21 June 2020.

35. Dhruv G. Effect of ambient temperature on COVID-19 infection rate. SSRN 2020. http://dx.doi.org/10.2139/ssrn.3358470.

36. Gandhi M, Yokoe SD, Havlir D. Asymptomatic transmission, the Achilles? heel of current strategies to control COVID-19. N Engl J Med. 2020;382(22):2158-60.

37. Matto $P$, Gianluca R. An empirical estimate of the infection fatality rate of COVID-19 from first Italian outbreak. SSRN. 2020. http://dx.doi.org/10. 2139/ssrn.3582811.

38. Basu A. Estimating the infection fatality rate among symptomatic COVID-19 cases in The United States. Health Aff. 2020;39(7):1229-36.

39. Fraser C, Donnelly CA, Cauchemez S, Hanage WP, Van Kerkhove MD, Hollingsworth TD, Griffin J, Baggaley RF, Jenkins HE, Lyons EJ, et al. Pandemic potential of a strain of influenza $A(H 1 N 1)$ : early findings. Science. 2009;324(5934):1557-61.

40. Wangping J, Ke H, Yang S, Wenhe C, Shengshu W, et al. Extended SIR prediction of the epidemics trend of COVID-19 in Italy and compared with Hunan China. medRxiv. 2020. https://doi.org/10.1101/2020.03.18. 20038570

41. Gumel AB, Ruan SG, Day T, Watmough J, Brauer F, Van den Driessche P, Gabrielson D, Bowman C, Alexander ME, Ardal S, et al. Modelling stratigies for controlling SARS outbreaks. Proc R Soc Lond B Biol Sci. 2004;271:2223-32.

42. Majumder MS, Rivers C, Lofgren E, Fisman D. Estimation of MERS-coronavirus reproductive number and case fatality rate for the spring 2014 Saudi Arabia outbreak: insights from publicly available data. PLoS Curr. 2014. https://dx.doi.org/10.1371\%2Fcurrents.outbreaks. 98d2f8f3382d84f390736cd5f5fe133c.

\section{Publisher's Note}

Springer Nature remains neutral with regard to jurisdictional claims in published maps and institutional affiliations.

\section{Ready to submit your research? Choose BMC and benefit from}

- fast, convenient online submission

- thorough peer review by experienced researchers in your field

- rapid publication on acceptance

- support for research data, including large and complex data types

- gold Open Access which fosters wider collaboration and increased citations

- maximum visibility for your research: over $100 \mathrm{M}$ website views per year

At BMC, research is always in progress.

Learn more biomedcentral.com/submissions 